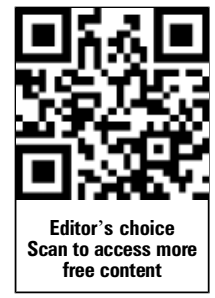

- Additional material is published online only. To view please visit the journal online (http://dx.doi.org/10.1136/ archdischild-2012-302383).

1 Department of Primary Care Health Sciences, University of Oxford, Oxford, UK 2Unit of Health-Care Epidemiology, Department of Public Health, University of Oxford, Oxford, UK ${ }^{3}$ Department of Paediatric Respiratory Medicine, Oxford Children's Hospital, Oxford, UK

Correspondence to Peter J Gill, Department of Primary Care Health Sciences, University of Oxford, Radcliffe Observatory Quarter, Woodstock Road, Oxford OX2 6GG, UK; peter.gill@phc.ox.ac.uk

Received 21 May 2012 Revised 26 December 2012 Accepted 7 January 2013 Published Online First 12 February 2013

\section{SLinked}

- http://dx.doi.org/10.1136/ archdischild-2012-303562

To cite: Gill PJ, Goldacre MJ, Mant D, et al. Arch Dis Child

2013;98:328-334.

\title{
Increase in emergency admissions to hospital for children aged under 15 in England, 1999-2010: national database analysis
}

\author{
Peter J Gill, ${ }^{1}$ Michael J Goldacre, ${ }^{2}$ David Mant, ${ }^{1}$ Carl Heneghan, ${ }^{1}$ Anne Thomson, ${ }^{3}$ \\ Valerie Seagroatt, ${ }^{2}$ Anthony Harnden ${ }^{1}$
}

\section{ABSTRACT}

Objective To investigate a reported rise in the emergency hospital admission of children in England for conditions usually managed in the community. Setting and design Population-based study of hospital admission rates for children aged under 15, based on analysis of Hospital Episode Statistics and population estimates for England, 1999-2010.

Main outcome Trends in rates of emergency admission to hospital.

Results The emergency admission rate for children aged under 15 in England has increased by 28\% in the past decade, from 63 per 1000 population in 1999 to 81 per 1000 in 2010. A persistent year-on-year increase is apparent from 2003 onwards. A small decline in the rates of admissions lasting 1 day or more has been offset by a twofold increase in short-term admissions of $<1$ day. Considering the specific conditions where high emergency admission rates are thought to be inversely related to primary care quality, admission rates for upper respiratory tract infections rose by $22 \%$, lower respiratory tract infections by $40 \%$, urinary tract infections by $43 \%$ and gastroenteritis by $31 \%$, while admission rates for chronic conditions fell by $5.6 \%$.

Conclusions The continuing increase in very-short-term admission of children with common infections suggests a systematic failure, both in primary care (by general practice, out-of-hours care and National Health Service Direct) and in hospital (by emergency departments and paediatricians), in the assessment of children with acute illness that could be managed in the community. Solving the problem is likely to require restructuring of the way acute paediatric care is delivered.

\section{INTRODUCTION}

Life-threatening emergencies such as epiglottitis and meningitis are at an all-time low, yet the number of children being admitted to hospital as emergencies seems to be increasing every year. ${ }^{1}$ Unplanned hospital admission is costly for the healthcare system and for children, straining finite hospital resources. Once admitted, children are at risk of hospital-acquired infections, medical errors, drug reactions and emotional trauma. ${ }^{2}$ Moreover, the UK National Health Service (NHS) Outcomes Framework for 2012/13 specifies a reduction in unplanned hospital admissions for children as a health improvement target. ${ }^{3}$

Over the past decade, there have been several major structural reforms to the NHS in England. In 2000, the government introduced a target for hospital emergency departments specifying that no

\section{What is already known on the topic}

- Hospital paediatricians report that the number of children being admitted to hospital as emergencies seems to be increasing every year in the National Health Service (NHS) in England.

- Unplanned admissions strain healthcare resources and may place children at risk of hospital-acquired infections, medical errors, drug reactions and emotional trauma.

- There have been several major structural reforms to the NHS in England over the past decade.

\section{What this study adds}

- There has been a year-on-year rise in emergency admissions to hospitals in England since 2003, particularly short-term admissions in the under five age group.

- Much of this rise is for common infections, suggesting a systematic failure of the NHS in assessing children with acute illness that could be managed in the community.

- The timing suggests that the $4 \mathrm{~h}$ wait target in emergency departments and the change to general practitioners out-of-hours care may have played an important role.

patient should wait more than 4 h. $^{4}$ This was gradually implemented over the next 3 years so that $23 \%$ of patients spent over $4 \mathrm{~h}$ in the emergency department in 2002, but by mid-2004 only 5.3\% stayed that long. ${ }^{5}$ In 2004, the NHS implemented a new contract which split in-hours and out-of-hours work in primary care, ${ }^{6}$ allowing general practitioners to opt out of providing acute care in the evenings and weekends. Now only $10 \%$ of general practitioners provide this care, and the responsibility has shifted to NHS Primary Care Trusts who contract with a range of public and private providers. ${ }^{7}$

A 2009 analysis of English hospital data reported a $22 \%$ increase in unplanned short-stay admissions in children aged 10 and younger between 1997 and $2006 .{ }^{8}$ The authors suggested that in part this 'may 
be evidence of a failure of primary care services'. ${ }^{8}$ Indeed, most unplanned admissions for children now occur out-of-hours and there is evidence of changing parental attitudes to healthcare services. ${ }^{9-11}$ Increased attendance of anxious parents will in itself increase pressure on relatively inexperienced junior doctors, working shorter shifts than previously, and under pressure to achieve the $4 \mathrm{~h}$ waiting time target. ${ }^{8}$ However, there have also been other changes to hospital provision that might impact on admission rates such as an increase in short-stay units, adoption of care pathways that discourage paediatric assessment before formal admission, and increased use of rapid-result technology during routine assessment.

We report an analysis of emergency admissions of children in England by age and length of stay. We hypothesised that, if there had been a lowering of the threshold for hospital admission as a result of changes in the UK healthcare system, we should observe an escalation in rate of emergency admissions for ambulatory-care-sensitive conditions (those acute conditions that are usually managed in the community). ${ }^{12}$ However, any change in admission rates is likely to be multifactorial, reflecting the significant changes that have taken place in the hospital sector and in parental attitudes, as well as in primary care.

\section{METHODS}

We used Hospital Episode Statistics (HES) and Office for National Statistics mid-year population estimates for England to calculate age-specific hospital admission rates for emergency care between 1 January 1999 and 31 December 2010. Numbers given are based on episodes of care defined as 'continuous inpatient spells', which refers to the continuous time spent in hospital from admission to discharge regardless of any withinhospital transfers. When individual children were admitted more than once, each admission was counted. Length of stay was calculated by subtracting the admission date from the discharge date of each episode of continuous inpatient care.

The choice of specific conditions and codes was based on Purdy's analysis of ambulatory-care-sensitive conditions relevant to NHS practice; of the 19 conditions identified that are defined by ICD-10 (International Classification of Diseases, 10th revision) codes commonly used in the NHS, we used the eight of relevance to children. ${ }^{12}$ For four of these eight, we applied the coding defined by the NHS Outcomes Framework 2012/13. ${ }^{3}$ The ICD-10 codes for the eight conditions are outlined in online supplementary table S1.

We used PASW Statistics 18.0 to analyse all emergency admissions and the eight conditions. We divided children's ages into four groups ( $<1,1-4,5-9$ and 10-14 years) and reported treatment lengths of $<1$ day (admission without an overnight stay), 1-2 days and $>2$ days. We calculated the cumulative percentage change in admission rate since 1999 by calculating ((rate in 2000 -rate in 1999)/rate in 1999) $\times 100$ for each subsequent year from 2001 to 2010 . We calculated the overall change in admission rate by calculating (rate in 2010 /rate in 1999) $\times 100$. We report age-specific rates per thousand children in each age group and the average annual change, annual cumulative change and cumulative change from 1999 as percentages.

\section{RESULTS}

Figure 1 shows that the total number of emergency admissions in children aged $<15$ years has increased by $24 \%$ (from 593850 to 738805 ) and admission rates have increased by $28 \%$ (from 63 to 81 per 1000 , table 1 ). The greatest rise in numbers of admissions was in children aged $<5$ years. Admissions of children $<1$ increased by $52 \%$, and aged $1-4$ by $25 \%$. In 2010 , two-thirds of admissions (68\%, 500935 of 738805) were for children aged under 5 .

Emergency admission rates for other age groups also increased substantially (table 1 ). In all children $<15$ years, a rise in admission was observed every year from 2003 onwards, with a mean increase of $3.8 \%$ annually in $2003-6$ and $2.5 \%$ in 2007-10.

Figure 2 (also see online supplementary table S2) shows the change in length of admission over the past decade. Admissions lasting < 1 day increased twofold (from 18 to 37 per 1000; from 172532 to 335038 ) over the 12 -year period, and the rise was broadly consistent across all age groups (age <1, 104\%; age
Figure 1 Number of emergency admissions of children aged $<15$ years in England each year 1999-2010.

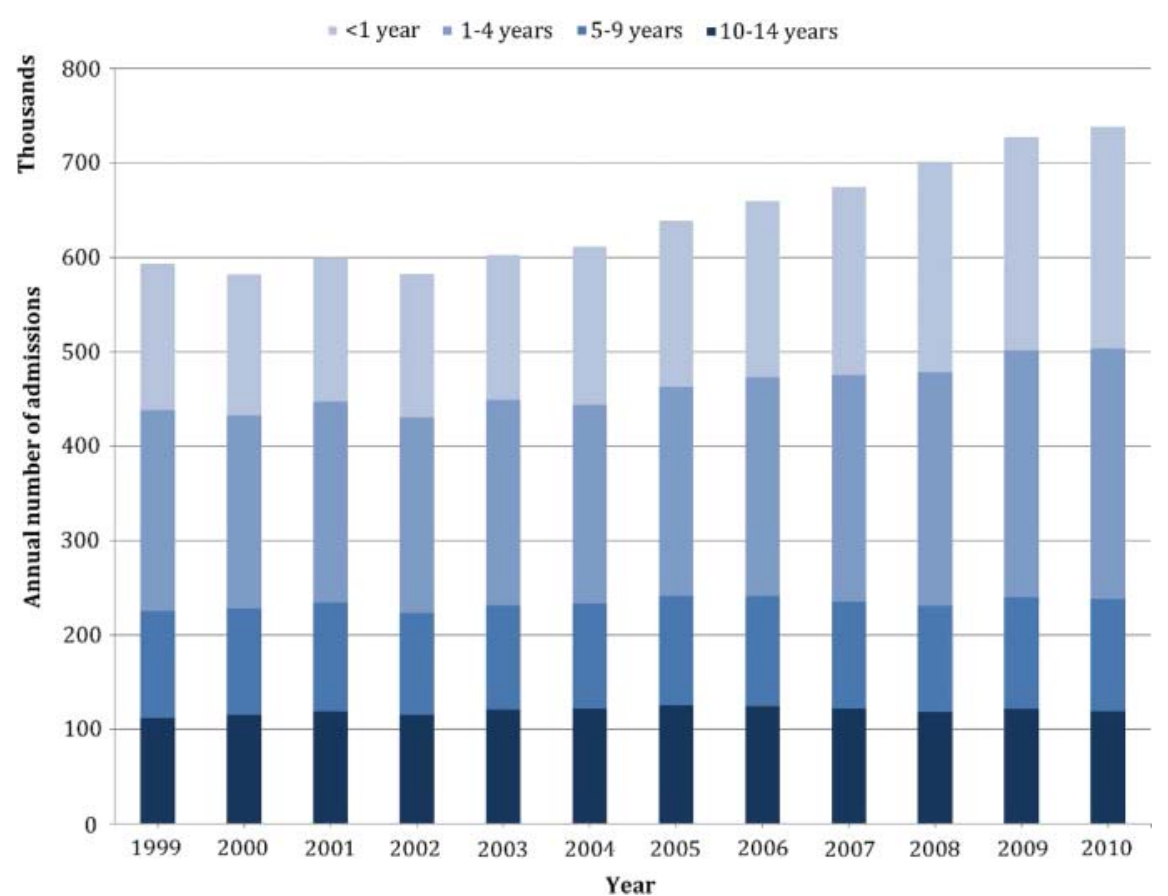


Table 1 Trends in annual rate of emergency admissions to hospital for children in England by age, 1999-2010

\begin{tabular}{|c|c|c|c|c|c|c|c|c|c|c|c|c|c|c|c|}
\hline \multirow{2}{*}{ Year } & \multicolumn{3}{|c|}{ All $<15$ years } & \multicolumn{3}{|l|}{ Age $<1$ year } & \multicolumn{3}{|c|}{ Age $1-4$ years } & \multicolumn{3}{|c|}{ Age $5-9$ years } & \multicolumn{3}{|c|}{ Age $10-14$ years } \\
\hline & $\begin{array}{l}\text { Event rate } \\
\text { (per 1000) }\end{array}$ & $\begin{array}{l}\text { Annual } \\
(\%)^{*}\end{array}$ & $\begin{array}{l}\text { Cumulative } \\
(\%) \dagger\end{array}$ & $\begin{array}{l}\text { Event rate } \\
\text { (per 1000) }\end{array}$ & $\begin{array}{l}\text { Annual } \\
(\%)^{*}\end{array}$ & $\begin{array}{l}\text { Cumulative } \\
(\%) \dagger\end{array}$ & $\begin{array}{l}\text { Event rate } \\
\text { (per 1000) }\end{array}$ & $\begin{array}{l}\text { Annual } \\
(\%)^{*}\end{array}$ & $\begin{array}{l}\text { Cumulative } \\
(\%) \dagger\end{array}$ & $\begin{array}{l}\text { Event rate } \\
\text { (per 1000) }\end{array}$ & $\begin{array}{l}\text { Annual } \\
(\%)^{*}\end{array}$ & $\begin{array}{l}\text { Cumulative } \\
(\%) \dagger\end{array}$ & $\begin{array}{l}\text { Event rate } \\
\text { (per 1000) }\end{array}$ & $\begin{array}{l}\text { Annual } \\
(\%)^{*}\end{array}$ & $\begin{array}{l}\text { Cumulative } \\
(\%) \dagger\end{array}$ \\
\hline 1999 & 63 & - & - & 263 & - & - & 88 & - & - & 35 & - & - & 35 & - & - \\
\hline 2000 & 62 & -1.3 & -1 & 260 & -0.8 & -1 & 85 & -2.8 & -3 & 35 & 0 & 0 & 36 & +2.4 & +2 \\
\hline 2001 & 65 & +3.9 & +2 & 275 & +5.4 & +5 & 90 & +5.8 & +3 & 37 & +4.8 & +5 & 37 & +1.2 & +4 \\
\hline 2002 & 63 & -2.2 & 0 & 272 & -0.8 & +4 & 90 & -0.2 & +3 & 35 & -5.7 & -1 & 35 & -3.2 & 0 \\
\hline 2003 & 66 & +4.2 & +4 & 268 & -1.7 & +2 & 96 & +6.6 & +9 & 36 & +4.0 & +3 & 37 & +4.6 & +5 \\
\hline 2004 & 67 & +2.0 & +7 & 280 & +4.7 & +7 & 93 & -2.6 & +7 & 37 & +1.3 & +4 & 38 & +2.2 & +7 \\
\hline 2005 & 71 & +5.1 & +12 & 291 & +3.7 & +11 & 97 & +3.7 & +11 & 39 & +5.9 & +10 & 39 & +4.0 & +12 \\
\hline 2006 & 73 & +3.8 & +16 & 301 & +3.5 & +15 & 99 & +2.7 & +14 & 40 & +2.5 & +13 & 40 & +1.0 & +13 \\
\hline 2007 & 75 & +2.3 & +19 & 310 & +3.2 & +18 & 100 & +0.7 & +14 & 39 & -1.1 & +12 & 40 & -0.6 & +12 \\
\hline 2008 & 78 & +3.6 & +23 & 334 & +7.6 & +27 & 101 & +0.6 & +15 & 39 & -0.1 & +12 & 39 & -2.1 & +10 \\
\hline 2009 & 80 & +3.2 & +27 & 340 & +1.8 & +30 & 103 & +2.8 & +18 & 41 & +4.6 & +17 & 40 & +4.0 & +14 \\
\hline 2010 & 81 & +0.7 & +28 & 349 & +2.6 & +33 & 102 & -1.1 & +17 & 41 & -0.8 & +16 & 40 & -0.8 & +13 \\
\hline \multicolumn{16}{|c|}{ Average annual change $(\%) \ddagger$} \\
\hline $\begin{array}{l}1999- \\
2002\end{array}$ & - & +0.1 & - & - & +1.3 & - & - & +0.9 & - & - & -0.3 & - & - & +0.1 & - \\
\hline $\begin{array}{l}2003- \\
2006\end{array}$ & - & +3.8 & - & - & +2.6 & - & - & +2.6 & - & - & +3.4 & - & - & +3.0 & - \\
\hline $\begin{array}{l}2007- \\
2010\end{array}$ & - & +2.5 & - & - & +3.8 & - & - & +0.7 & - & - & +0.6 & - & - & +0.1 & - \\
\hline
\end{tabular}

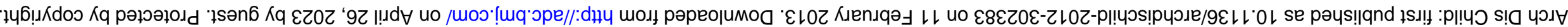



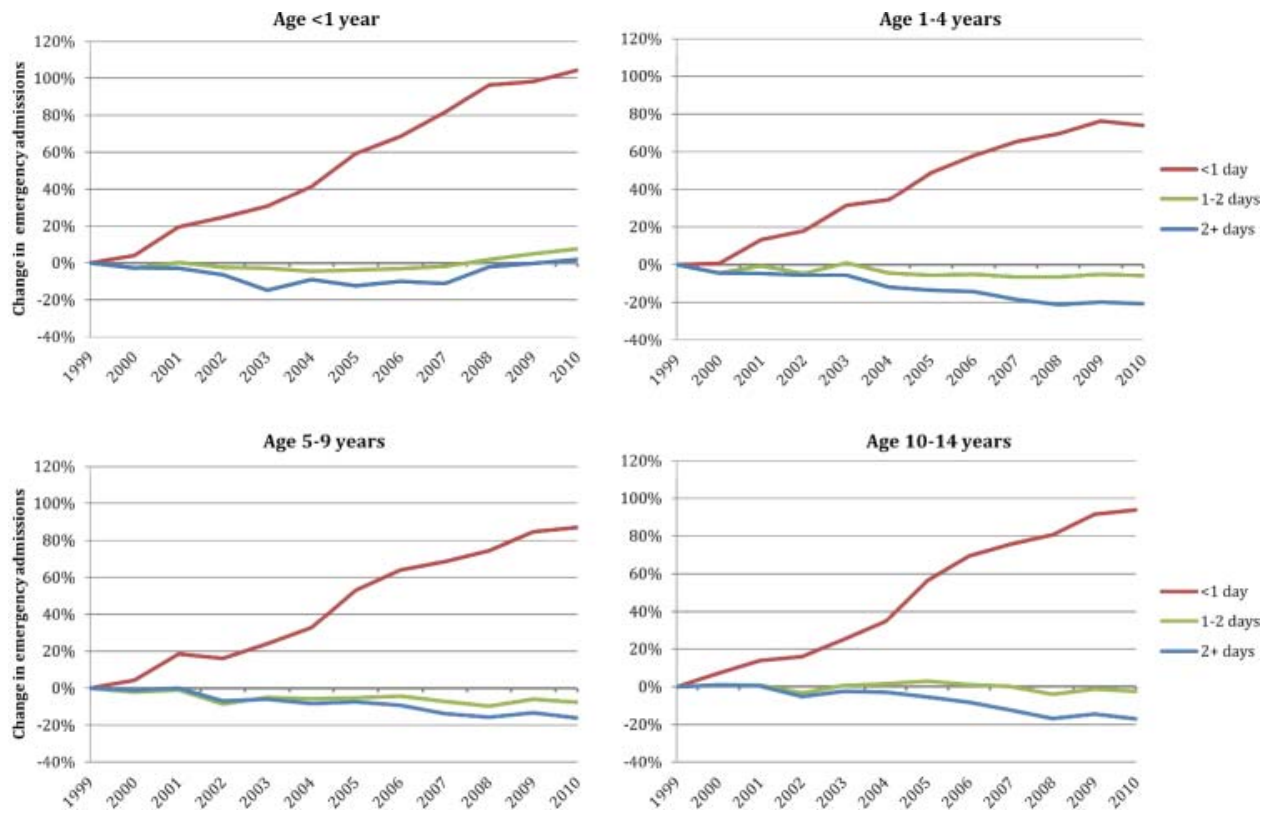

Figure 2 Percentage change since 1999, expressed as cumulative change from 1999, in rates of admissions of different duration by age group.

$1-4,74 \%$; age 5-9, 87\%; age 10-14, 94\%). Although there has been a small decrease in the number of admissions $>2$ days $(-8.8 \%)$, there was minimal change in the number of $1-2$ day admissions $(+0.2 \%)$.

The total number of admissions for primary-care-sensitive conditions rose $18 \%$ (from 172532 to 335038 ; from 19 to 23 per $1000)$. The increase was in acute conditions (26\% increase) rather than chronic conditions (8.3\% decrease).

Figures 3 and 4 illustrate the difference between rates of admission for the four acute infections (upper and lower respiratory tract infections, gastroenteritis and urinary tract infections), which rose by $30 \%$ (from 14.5 to 18.9 per 1000), and for the three chronic conditions (asthma, diabetes and epilepsy), which fell by $5.6 \%$ (from 4.3 to 4.0 per 1000) between 1999 and 2010 (see online supplementary table S3). The increase in number of admissions for the individual primary-care-sensitive acute infections was: upper respiratory tract infections, $18 \%$ (from 56286 to 66505 ); lower respiratory tract infections, 36\% (from 31711 to 43080 ); urinary tract infections, 39\% (from 8799 to 12 208); gastroenteritis, 27\% (from 40120 to 50 958). Asthma was the most common cause of a primary-care-sensitive admission for a chronic condition in every year, accounting for $64-73 \%$ of all admissions for chronic conditions.

Overall, there was a modest fall in admissions for chronic conditions. The $48 \%$ rise in the number of $<1$ day admissions
Figure 3 Percentage change since 1999, expressed as cumulative change from 1999, in rate of admissions of children for the acute infections normally managed in primary care. Note: All acute infections includes upper and lower respiratory tract infection, urinary tract infection and gastroenteritis. LRTI, lower respiratory tract infection; URTI, upper respiratory tract infection; UTI, urinary tract infection.

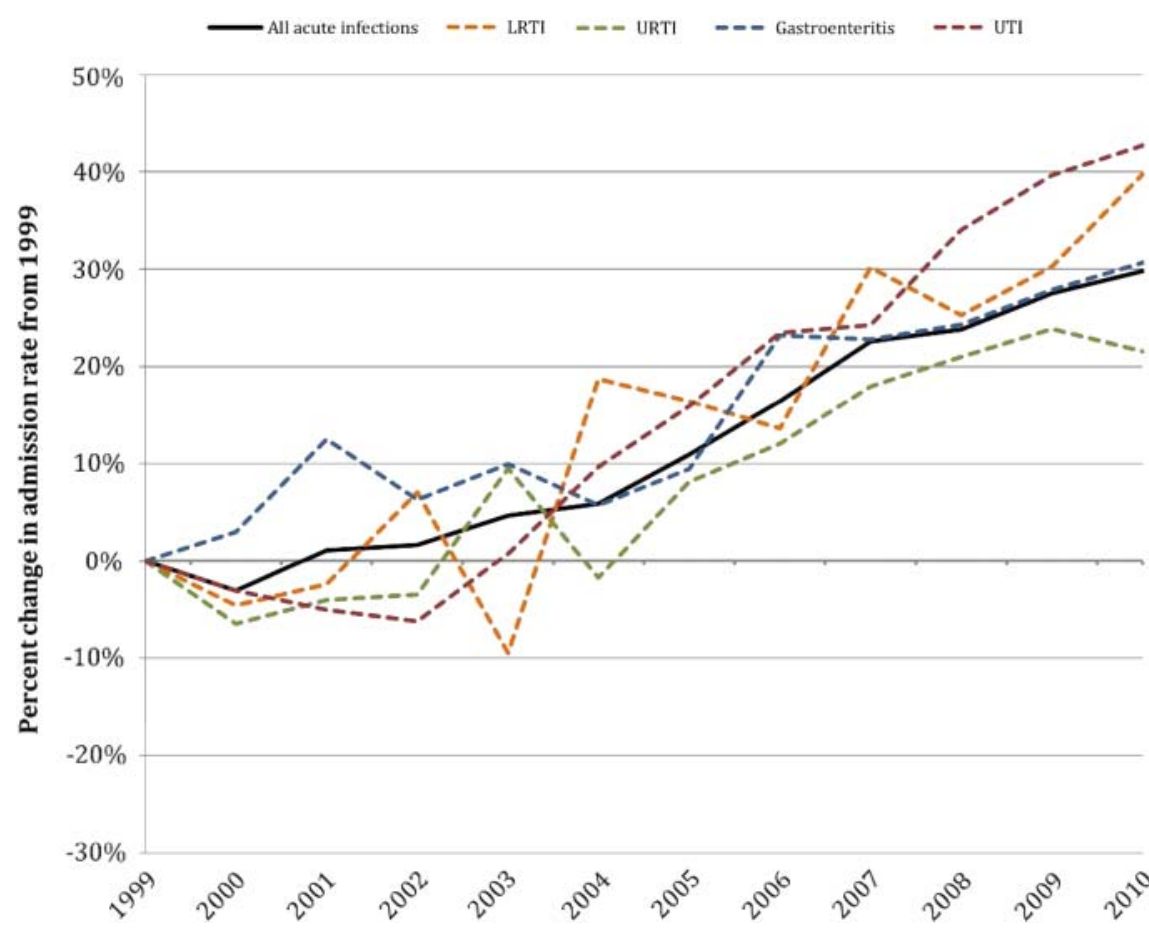



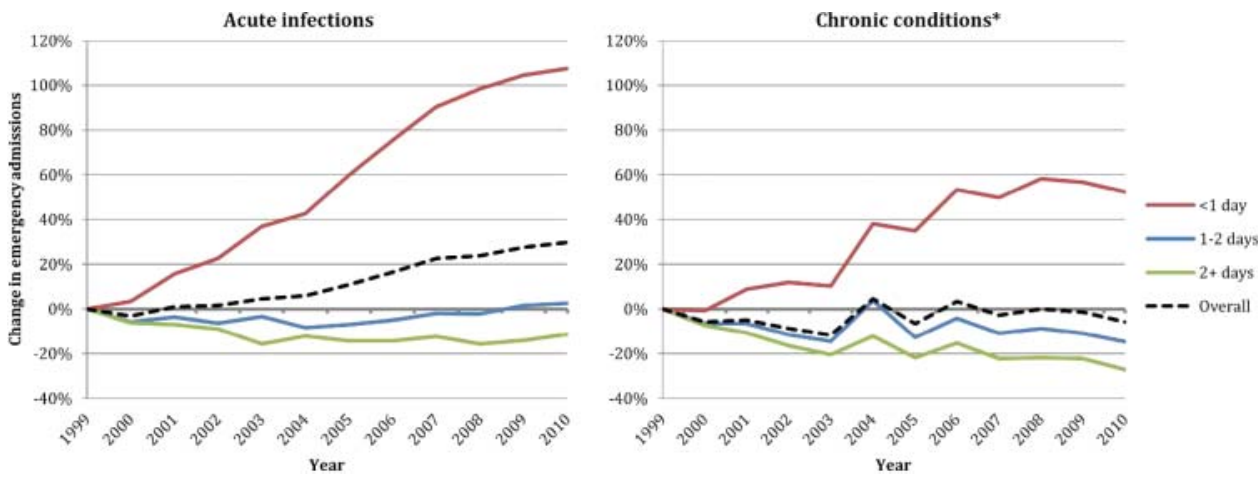

Figure 4 Percentage change since 1999, expressed as cumulative change from 1999, in rates of admissions of different duration. The acute infections included are upper and lower respiratory tract infection, urinary tract infection and gastroenteritis; the chronic conditions are asthma, diabetes and epilepsy. * Of the chronic conditions, asthma comprises $64-73 \%$ of all admissions.

for asthma, diabetes and epilepsy was contrasted by a $17 \%$ fall in 1-2 day admissions and a $28 \%$ fall in $>2$ day admissions. The number of vaccine-preventable admissions fell from 1053 in 1999 to 385 in 2010.

\section{DISCUSSION}

The findings confirm that the rise in numbers of emergency admissions of children reported in 2002-2006 has continued year-on-year. The rise in emergency admission rates for older children has slowed in recent years, but in children $<5$ years it continues to increase at an annual rate of $\sim 3 \%$. If the rate continues to increase at $3 \%$ per year, population projections for England suggest that 731000 children aged $<5$ will be admitted as emergencies in 2020, which is 230000 more than are currently admitted. ${ }^{13}$

The increase in admissions does not reflect an increase in the number of very sick children. The number of deaths of children aged 1-14 years fell by 36\% in England and Wales during the study period (from 1581 in 1999 to 1006 in 2010), ${ }^{14}$ in part reflecting improved immunisation against causes of meningitis and pneumonia. Between 2006 and 2008, the childhood bacterial pneumonia admission rate decreased by $19 \%$ after the introduction of the PCV7 conjugate vaccination to the national childhood immunisation programme. ${ }^{15}$ Even where the country has chosen not to immunise, risk of death from acute infection remains very low. For example, between 1996 and 2004, there were only three deaths in England due to a primary diagnosis of rotavirus and 16 deaths due to a primary diagnosis of gastroenteritis in children under $5 .{ }^{16}$ In other words, the risk being mitigated by very-short-term hospital admission of children is low and is falling rather than increasing.

The initial rise in childhood admission rates in our data was coincidental with the gradual enforcement of the $4 \mathrm{~h}$ wait target in hospital emergency departments between 2000 and 2003. For example, the peaks in chronic disease admissions seen in figure 4 may reflect changes in national guidelines and care pathways for asthma, diabetes and epilepsy. However, the escalating increase after 2003 in very-short-term admission of children with conditions that are usually managed at home suggests an increasing failure of the NHS in assessing and managing children with acute self-limiting illness.

Previous authors have attributed this apparent failure to the 2004 changes to the NHS contractual arrangements for general practitioners, allowing them to opt out of providing out-of-hours care. ${ }^{8}$ The increasing admission of children for very-short-term care, particularly for acute infections, certainly suggests a reluctance of primary care to observe and manage sick children with self-limiting infections in the community. Assessments increasingly occur in a distant assessment centre rather than in the general practitioner's office-it is a much greater decision to refer a child to hospital from their local health centre.

However, temporal association does not prove causation-the past decade has also seen a number of other substantial changes in healthcare in the UK, including changes in the hospital sector, which may have impacted on admission rates during this period. The multiple factors that may have affected the emergency admissions of children are summarised in box 1 .

More children are being brought for assessment, both to primary care clinics and often direct to hospital. ${ }^{11}$ Better public education and information dissemination may have led to an increase in consultations due to better awareness of the potential red-flag symptoms in children, and there is also some evidence that some parents and carers of children with minor self-limiting complaints are increasingly reluctant to liaise with healthcare professionals and care for sick children at home. ${ }^{17}$ The health-seeking behaviours of parents is also likely to have been influenced by the introduction of NHS Direct, a protocol-led telephone service which often encourages the parent to take the child to be seen by a doctor and may advise parents to seek hospital care directly. This happened in 14\% of calls about children in one area surveyed in 2007, although we do not know how many children would have been taken straight to hospital if parents had not made the phone call. ${ }^{18}$

Other organisational changes in the NHS in the study period included the commissioning of walk-in centres, which may further act to fragment care across multiple providers, and the construction and dissemination of national guidance on the assessment and management of children by the National Institute for Health and Clinical Excellence. The widespread adoption of near-patient technology (such as oximetry) without clear understanding of its diagnostic value in settings with low disease prevalence has also been cited as a potentially important factor in lowering the threshold for admission from emergency departments ${ }^{19}$ and it may also have influenced the number of referrals from primary care.

An increase in the perceived risk of legal claims may be important in encouraging junior doctors to be risk averse. ${ }^{20}$ New models of acute paediatric care, such as short-stay units and emergency outpatient consultations, are emerging ${ }^{21-23}$ and these may have both lowered the threshold for admission and (by increasing the efficiency with which acute problems such as asthma and 
Box 1 Potential causes of the observed increase in very-short-term emergency admissions in children

- Increase in number of children being taken to primary care for assessment.

- Decrease in thresholds in primary care for referral of children to hospital.

- Increase in the number of parents being advised by National Health Service (NHS) Direct to take their child straight to hospital.

- Increase in the number of parents taking their child straight to hospital without first seeking NHS advice elsewhere.

- Decrease in willingness of parents and carers of children to care for them at home when they have minor self-limiting complaints.

- Decrease in willingness of parents and carers of children to tolerate uncertainty.

- Increase in decisions to admit rather than further observe in order to reach the $4 \mathrm{~h}$ emergency department wait target.

- Decrease in exposure to (and training for) triage of children with potentially serious illness during general practitioner training.

- Decrease in hospital clinicians' ability to triage effectively or to accept risk.

- Unintended financial incentives created by contracts and payment tariffs that reward admission.

- Introduction of rapid diagnostic technologies without clear understanding of their diagnostic value in situations where disease prevalence is low.

- Decrease in the length of stay of children admitted because of more rapid and effective treatment in short-stay units for acute conditions such as asthma and mild dehydration (from gastroenteritis).

dehydration are managed) have decreased the length of stay, thereby increasing the number of very-short-term admissions.

We believe our results are robust. Although the robustness of any time trend analysis is limited by possible variation in data completeness and the consistency of coding, we are not aware of any major changes in coding or completeness between 1999 and 2010 that would affect our findings. The effect of the $4 \mathrm{~h}$ wait limit introduced in emergency departments in 2000 may have led to the creation of short-stay facilities, such that children observed for longer than $4 \mathrm{~h}$ were counted as admissions without any change in clinical practice. Unfortunately, national HES data do not include the time of day that children were admitted and we did not evaluate re-admissions. Moreover, the data did not allow us to distinguish between the impact of increases in numbers of children being taken to hospital for assessment and increases in the percentage of assessed children being admitted.

We recognise that unplanned admission for primarycare-sensitive conditions can only be an indicator of quality at the level of the healthcare system in aggregate. Short-term hospital admission of an individual child may be very important for observation of the illness trajectory, ensuring a child can tolerate oral fluids, or managing an acute social problem. ${ }^{24}$ However, the eight conditions we used for this analysis, as conditions that should usually be cared for out of hospital, have been widely used as a measure of primary and ambulatory care quality in Europe, Australasia and North America. ${ }^{25-29}$ Although temporal association does not allow inference of causation, it is often possible to gain greater understanding by looking in detail at geographical variation in the NHS. We suggest that this may be a helpful next step in disentangling the complexity and identifying specific examples of good and not so good practice.

\section{CONCLUSIONS}

The continuing increase in very-short-term admission of children with common infections suggests a systematic failure, both in primary care (by general practice, out-of-hours care and NHS Direct) and in hospital (by emergency departments and paediatricians), in the assessment of children with acute illness that could be managed in the community. It may also reflect an increased reluctance by parents and doctors to tolerate uncertainty. Solving the problem of escalating hospital admissions of children is likely to require restructuring of the way acute paediatric care is delivered, particularly emergency and out-of-hours care. This restructuring must be conducted with empirical evaluation of the policy options.

Acknowledgements Leicester Gill and Matt Davidson from the Unit of Health-Care Epidemiology built the file used in this analysis.

Contributors PJG conceived the study. PJG, MJG, DM, CH, AT, VS and AH developed the study design. PJG and VS undertook the data analysis. PJG, DM and AH drafted the paper. All authors contributed to the interpretation of the data and revision of the manuscript. All authors had full access to all of the data (including statistical reports and tables) in the study and can take responsibility for the integrity of the data and the accuracy of the data analysis. PJG is guarantor for the study.

Funding PJG is funded by the Rhodes Trust and by Alberta Innovates-Health Solutions. PJG, DM, CH and AH are members of the National Institute for Health Research School of Primary Care. VS, and the Unit of Health-Care Epidemiology, is funded by the English National Institute for Health Research. The funding bodies had no role in the study design, in the collection, analysis, and interpretation of data, in the writing of the report, or in the decision to submit the article for publication. The views expressed in this paper are those of the authors and not necessarily those of the funding bodies.

Competing interests None.

Ethics approval NHS Central Office for Research Ethics Committees (04/Q2006/176)

Provenance and peer review Not commissioned; externally peer reviewed.

\section{REFERENCES}

1 Department of Health. Chief Nursing Officer's Directorate, Families \& Maternity Analysis. Trends in Children and Young People's Care: Emergency Admission Statistics, 1996/97-2006/07, England. 2008. http:/www.dh.gov.uk/en/ Publicationsandstatistics/Statistics/DH_083710 (accessed 9 Dec 2011).

2 Flores G. Preventing hospitalisations for children. Lancet 2005;365:201-2.

3 Department of Health. The NHS Outcomes Framework 2012-13: Technical Appendix. 2011. http://www.dh.gov.uk/en/Publicationsandstatistics/Publications/ PublicationsPolicyAndGuidance/DH_131700 (accessed 12 Jan 2012).

4 Department of Health. The NHS Plan: a plan for investment a plan for reform. 2000. http://www.dh.gov.uk/en/Publicationsandstatistics/Publications/ PublicationsPolicyandGuidance/DH_4002960 (accessed 28 Feb 2012).

5 Bevan $\mathrm{G}$, Hood C. Have targets improved performance in the English NHS? BMJ 2006;332:419-22.

6 Department of Health. Investing in general practice: the new general medical services contract. 2003. http://www.dh.gov.uk/en/Publicationsandstatistics/ Publications/PublicationsPolicyAndGuidance/DH_4071966 (accessed 28 Feb 2012).

7 National Audit Office. The provision of out-of-hours care in England. 2006. http:// www.nao.org.uk/publications/0506/out-of-hours_care_in_england.aspx (accessed 27 Feb 2012)

8 Saxena S, Bottle A, Gilbert R, et al. Increasing short-stay unplanned hospital admissions among children in England; time trends analysis '97-'06. PLoS One 2009; 4:e7484.

9 Stewart M, Werneke U, MacFaul R, et al. Medical and social factors associated with the admission and discharge of acutely ill children. Arch Dis Child 1998;79:219-24.

10 Hendry SJ, Beattie TF, Heaney D. Minor illness and injury: factors influencing attendance at a paediatric accident and emergency department. Arch Dis Child 2005;90:629-33.

11 Sands R, Shanmugavadivel D, Stephenson T, et al. Medical problems presenting to paediatric emergency departments: 10 years on. Emerg Med J 2012;29:379-82. 
12 Purdy S, Griffin T, Salisbury C, et al. Ambulatory care sensitive conditions: terminology and disease coding need to be more specific to aid policy makers and clinicians. Public Health 2009;123:169-73.

13 Office for National Statistics. National Population Projections, 2010-based projections. 2011. http://www.ons.gov.uk/ons/rel/npp/national-populationprojections/2010-based-projections/index.html (accessed 6 Mar 2012).

14 Office for National Statistics. Child Mortality Statistics 2010: childhood, infant and perinatal mortality in England and Wales. 2012. http://www.ons.gov.uk/ons/rel/ vsob1/child-mortality-statistics-childhood-infant-and-perinatal/2010/index.html (accessed 22 Jan 2013).

15 Koshy E, Murray J, Bottle A, et al. Impact of the seven-valent pneumococcal conjugate vaccination (PCV7) programme on childhood hospital admissions for bacterial pneumonia and empyema in England: national time-trends study, 1997-2008. Thorax 2010:65:770-4.

16 Jit $M$, Pebody $R$, Chen $M$, et al. Estimating the number of deaths with rotavirus as a cause in England and wales. Hum Vaccin 2007;3:23-6.

17 Kyle RG, Kukanova M, Campbell M, et al. Childhood disadvantage and emergency admission rates for common presentations in London: an exploratory analysis. Arch Dis Child 2011;96:221-6.

18 National Health Service South Central. Our NHS Our Future: Next stage review. South Central Clinical Pathway Group Report. Children and Young People. 2007.

19 Schuur JD, Venkatesh AK. The growing role of emergency departments in hospital admissions. N Engl J Med 2012;367:391-3.
20 Coon JT, Martin A, Abdul-Rahman AK, et al. Interventions to reduce acute paediatric hospital admissions: a systematic review. Arch Dis Child 2012;97: 304-11.

21 Macy ML, Kim CS, Sasson C, et al. Pediatric observation units in the United States: a systematic review. J Hosp Med 2010;5:172-82.

22 Williams L, Fryer J, Andrew $\mathrm{R}$, et al. Setting up a paediatric rapid access outpatient unit: views of general practice teams. BMC Fam Pract 2008;9:54.

23 Levett I, Berry K, Wacogne I. Review of a paediatric emergency department observation unit. Emerg Med J 2006;23:612-3.

24 Hill AM. Trends in paediatric medical admissions. BMJ 1989:298:1479-83.

25 Caminal J, Starfield B, Sanchez E, et al. The role of primary care in preventing ambulatory care sensitive conditions. Eur J Public Health 2004;14:246-51.

26 Tom JO, Tseng CW, Davis J, et al. Missed well-child care visits, low continuity of care, and risk of ambulatory care-sensitive hospitalizations in young children. Arch Pediatr Adolesc Med 2010;164:1052-8.

27 Agha MM, Glazier RH, Guttmann A. Relationship between social inequalities and ambulatory care-sensitive hospitalizations persists for up to 9 years among children born in a major Canadian urban center. Ambul Pediatr 2007;7:258-62.

28 Ansari Z, Laditka JN, Laditka SB. Access to health care and hospitalization for ambulatory care sensitive conditions. Med Care Res Rev 2006;63:719-41.

29 Bindman AB, Chattopadhyay A, Auerback GM. Medicaid re-enrollment policies and children's risk of hospitalizations for ambulatory care sensitive conditions. Med Care 2008;46:1049-54. 


\section{Correction}

Gill PJ, Goldacre MJ, Mant D, et al. Increase in emergency admissions to hospital for children aged under 15 in England, 1999-2010: national database analysis (Arch Dis Child 2013;98:32834). A numeric error was introduced by the journal's production team. In the Results, it reads: "The total number of admissions for primary-care-sensitive conditions rose $18 \%$ (from 172532 to 335038; from 19 to 23 per 1000).” The numbers in bold are incorrect. The correct sentence and numbers should be as follows: "The total number of admissions for primary-care-sensitive conditions rose $18 \%$ (from 178043 to 209898; from 19 to 23 per 1000)." We would like to apologise to the authors for this mistake.

Arch Dis Child 2013;98:651.

doi:10.1136/archdischild-2012-302383corr 1 